BMJ Open Ophthalmology

\section{Repeatability of choroidal thickness measurements with Spectralis OCT images}

To cite: Lau JK, Cheung SW, Collins MJ, et al. Repeatability of choroidal thickness measurements with Spectralis OCT images. BMJ Open Ophthalmology 2019;4:e000237. doi:10.1136/ bmjophth-2018-000237

Received 11 October 2018 Revised 21 February 2019 Accepted 6 April 2019
Check for updates

\section{c) Author(s) (or their} employer(s)) 2019. Re-use permitted under CC BY-NC. No commercial re-use. See rights and permissions. Published by BMJ.

${ }^{1}$ School of Optometry, The Hong Kong Polytechnic University, Hung Hom, Hong Kong ${ }^{2}$ School of Optometry and Vision Science, Queensland University of Technology, Brisbane, Queensland, Australia

Correspondence to Mr Jason K Lau; kklau@polyu. edu.hk

\section{ABSTRACT}

Objective To investigate the repeatability of choroidal thickness measurements determined from enhanced depth imaging optical coherence tomography (EDI-OCT) images of eyes after wearing single-vision spectacles (SV) and orthokeratology (ortho-k) lenses.

Methods and analysis Two EDI-OCT images of 40 children (SV: 20, ortho-k: 20) taken at a single visit were analysed twice. Subjects in the ortho-k group had been wearing ortho-k for 1-4 weeks. The choroidal thickness was determined from each image using a graph theorybased software and, where appropriate, manual correction of choroidal boundaries was undertaken by an experienced examiner.

Results The mean $( \pm \mathrm{SD})$ choroidal thickness was $227.3 \pm 42.2 \mu \mathrm{m}$ for the SV subjects and $251.1 \pm 54.4 \mu \mathrm{m}$ for the ortho-k subjects. The interimage differences in choroidal thickness were $-0.99 \pm 3.54$ and $-1.14 \pm 5.03 \mu \mathrm{m}$ for the SV and ortho-k subjects, respectively, and the limits of agreement were +5.96 to -7.93 and +8.72 to -11.00 $\mu \mathrm{m}$, respectively.

Conclusion The coefficients of repeatability of choroidal thickness measurements from two EDI-OCT images taken at a single visit were $7.08 \mu \mathrm{m}$ (SV) and $10.06 \mu \mathrm{m}$ (ortho-k), suggesting that a change in choroidal thickness of less than $10 \mu \mathrm{m}$ may not indicate a real change resulting from ortho-k lens wear.

\section{INTRODUCTION}

The choroid, a thin elastic vascular structure between the retina and the sclera of the eye, is known to play several roles. Apart from providing oxygen and nutrients to the outer retina, it is also important in thermoregulation, ${ }^{1}$ drainage of aqueous humour in the uveoscleral outflow, ${ }^{2}$ adjustment of the retinal position, ${ }^{34}$ secretion of growth factors ${ }^{5}$ and, possibly, ocular elongation (see review by Nickla and Wallman). ${ }^{6}$

Myopic defocus imposed with a positive lens leads to an increase in the choroidal thickness, whereas hyperopic defocus with a negative lens results in thinning in both animal $^{7}$ and human ${ }^{8-10}$ studies. Such changes in choroidal thickness result in anterior or posterior displacement of the retina towards the image plane and lead to decreased or

\section{Key messages}

What is already known about this subject?

The repeatability of choroidal thickness measurement varied between examiners and semiautomated segmentation improves its detection for subtle changes.

\section{What are the new findings?}

- The coefficients of repeatability of choroidal thickness measurements using a semiautomated software were $7.08 \mu \mathrm{m}$ and $10.06 \mu \mathrm{m}$ for subjects wearing single-vision spectacles and orthokeratology, respectively.

How might these results change the focus of research or clinical practice?

A change in choroidal thickness of less than $10 \mu \mathrm{m}$ may not indicate a real change in choroidal thickness after orthokeratology treatment.

increased growth of the eyeball in chicks. ${ }^{7}$ The changes in choroidal thickness may be associated with the changes in axial length in an approximate antiphase relationship. ${ }^{8}$

For many years, the ultrasound biometer has been used to measure axial length, ${ }^{11}$ anterior segment structures ${ }^{12}$ and posterior segment components. ${ }^{13}$ However, the use of advanced technology, in the form of optical coherence tomography (OCT), provides greatly improved images and more accurate measurements, so is the instrument of choice in research. A typical $10-\mathrm{MHz}$ ultrasound instrument provides an axial resolution of approximately $200 \mu \mathrm{m}$ and a transverse resolution of $500 \mu \mathrm{m}$. In contrast, a spectral-domain OCT with a $870 \mathrm{~nm}$ super luminescent diode (Spectralis OCT; Heidelberg Engineering, Heidelberg, Germany) provides $40 \quad 000$ A-scans per second and cross-sectional images with axial and lateral resolutions of 3.9 and 11 $\mu \mathrm{m}$, respectively. The use of ultrasound biometry also requires topical local anaesthetic which may induce ocular adverse events, such as contact dermatitis and subconjunctival haemorrhages, ${ }^{14}$ and possible measurement 
errors due to misalignment of the probe ${ }^{15}$ which make it less valuable for measuring axial length and choroidal thickness in children. OCT, on the other hand, does not have such limitations.

Spaide $e t a l^{16}$ described enhanced depth imaging OCT (EDI-OCT) which involves placing the instrument closer to the eye, which reduces the displacement of deeper structures from zero delay in order to obtain better visualisation of images. This technique has been widely used in the field for obtaining choroidal thickness ${ }^{17-21}$ and assessing ocular diseases. ${ }^{22-27}$ The Spectralis OCT also provides eye-tracking and image averaging functions which allow for evaluation of localised changes in retinal and choroidal thickness at follow-up visits.

In most published studies, ${ }^{28-33}$ choroidal thickness was determined manually due to the unavailability of built-in functions. It has been shown that the coefficient of repeatability (CR) of the interimage repeatability (in which images were captured consecutively at the same visit) was about $35 \mu \mathrm{m} .{ }^{30}{ }^{34}$ With the help of image processing and analysis software, Boonarpha et $a l^{85}$ measured choroidal thickness using manually marked boundaries and showed an overall CR of $54 \mu \mathrm{m}$ in choroids of different contours and shapes. However, manual procedures involved for choroidal segmentation requires longer execution time ${ }^{36}$ and subjective variation in determination of chorioscleral interface (CSI) could lead to substantial measurement errors and bias. To reduce the error of subjective discrepancies involved in the procedures, automated methods have been proposed. Alonso-Caneiro $e t a l^{37}$ developed a software for automatic segmentation of choroidal thickness with a smooth spline-fit function based on graph theory which facilitates the detection of the choroidal boundaries with minimal subjective judgements. They demonstrated agreement between manual and their proposed algorithm with a limit of agreement (LoA) of +35.37 to $-30.79 \mu \mathrm{m}$ for data from both children and adults. Twa $e t a l^{88}$ also used a software using analysis of graph theory and dynamic programming and produced a comparable repeatability of choroidal thickness to manual segmentation (where the LoA of manual and automatic measurements were \pm 15 and $\pm 14 \mu \mathrm{m}$, respectively). However, the repeatability of using the proposed algorithm in measuring choroidal thickness in children, especially those receiving myopic control treatment, is yet uncertain.

With increasing prevalence of myopia worldwide ${ }^{39} 40$ and associated pathologies with high myopia, ${ }^{41-43}$ many optical and pharmacological interventions have been investigated in controlling myopia in children (summarised by Huang et $a l) .{ }^{44}$ Orthokeratology (ortho-k) uses reverse-geometry rigid gas permeable lenses to affect ocular changes to slow myopia progres$\operatorname{sion}^{45-47}$ and is a popular optical method used for myopia control, especially in East Asian countries. ${ }^{48}$ A number of studies have reported about $50 \%$ slower axial elongation in children wearing ortho-k compared with control subjects wearing single-vision (SV) spectacles or contact lenses. ${ }^{45-51}$ Although two studies ${ }^{5253}$ have shown subfoveal choroidal thickening in subjects wearing ortho-k lenses for 1-6 months and suggested that this may be negatively correlated with some changes in axial length in early ortho-k treatment, another study ${ }^{54}$ did not observe any choroidal thickening after 9-month ortho-k treatment. Furthermore, central flattening and midperipheral steepening of the cornea after ortho-k lens wear ${ }^{55}$ may affect the magnification of OCT images and also choroidal thickness measurement. Thus, it is important to validate the repeatability of measurements in ortho-k treated children before confirmation of these changes.

Moreover, a few studies ${ }^{163156}$ have examined the repeatability of choroidal thickness measurement using correlation coefficients, but Bland and Altman ${ }^{57}$ reported this could be misleading and inappropriate and suggested using LoA and CR as repeatability parameters.

Therefore, the aim of this study was to determine and compare the repeatability of choroidal thickness measurement in spectacle-wearing and ortho-k wearing children using the semiautomated segmentation software on EDI-OCT images.

\section{METHODS}

The EDI-OCT scans were retrieved from two longitudinal ortho-k studies which were approved by the Departmental Research Committee of the School of Optometry at The Hong Kong Polytechnic University and registered at ClinicalTrial.gov (NCT02643875 and NCT02643342). Procedures performed were in accordance with the Declaration of Helsinki and informed consent was obtained from the parents after full explanation and disclosure of the objectives of the ortho-k research.

Subjects were Chinese aged 6 and 10 years (inclusive), with low myopia $(0.50-4.00 \mathrm{D})$ and low astigmatism $(\leq 1.25 \mathrm{D})$ in both eyes, and low anisometropia $(\leq 1.50$ $\mathrm{D})$. Their eyes were symmetrical in corneal topography ( $<2.00 \mathrm{D}$ difference). They had no prior myopia control experience nor any systemic or ocular conditions that could affect refractive development. A total of 40 healthy subjects were randomly selected, 20 wearing SV spectacles and 20 undergoing ortho-k treatment for 1-4 weeks.

The Spectralis OCT was used for capturing chorioretinal images. For each subject, three series of EDI-OCT images were taken, using the high-speed star scanning protocol, consisting of six $30^{\circ}$ long line scans, each separated by $30^{\circ}$, radially centred at the fovea. All the images were captured under EDI mode for enhanced visualisation of choroidal tissues. The automatic real-time mean was set to allow using the average of $30 \mathrm{~B}$-scans. The first image taken was treated as the reference image and served as the registration link for the following images. The 'Auto Rescan' function was applied in order to achieve sequential images of the same retinal location tracked by the confocal scanning laser ophthalmoscopy. The first two images captured for either eye (randomly selected) were used for data analysis. 

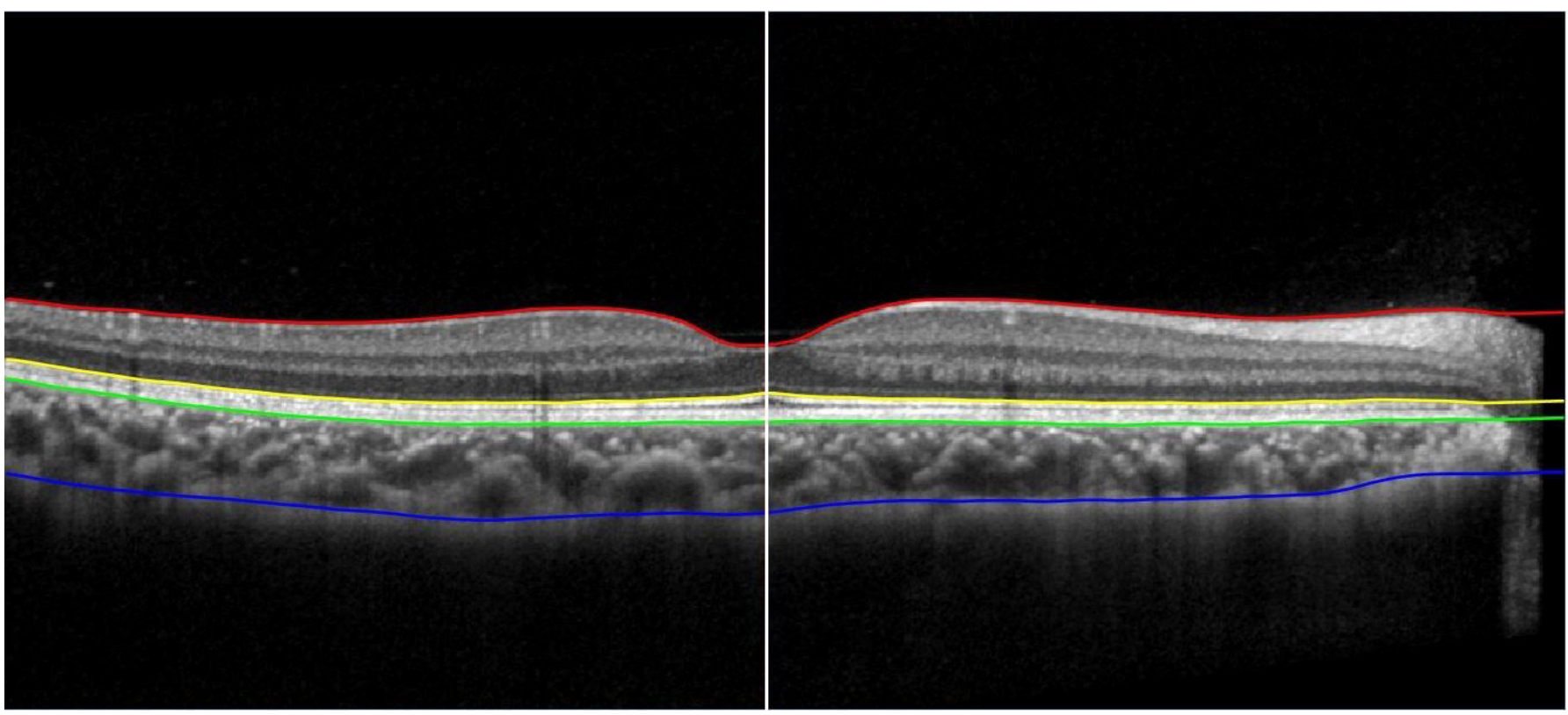

Figure 1 Segmented retinal and choroidal layers from the inner limiting membrane (red), the inner segment/outer segment junction (yellow), the outer retinal pigment epithelium (RPE)/Bruch's membrane complex (green) to the inner chorioscleral interface (CSI) (blue). The centre of the foveal pit was marked manually as the position of the thinnest retina (white). Choroidal thickness was determined as the thickness between the outer RPE/Bruch's membrane complex and the CSI.

The EDI-OCT images were then exported to custom written software for choroidal thickness segmentation. ${ }^{37}$ The measurements of choroidal thickness were performed using the horizontal line scans of the EDI-OCT images. Choroidal thickness was automatically determined as the thickness between the outer retinal pigment epithelium/ Bruch's membrane complex and the inner CSI. An experienced observer, masked to the treatment received by each subject, then manually corrected any segmentation errors in the boundary outlines generated by the software and determined the centre of the foveal pit, before the software derived the choroidal thickness. Figure 1 shows the outlines of different layers of the retina and the choroid as generated by the software and the centre of foveal pit determined by the observer. The measurements of the choroidal thickness for the second images were performed 4-6 weeks later to minimise subjective bias and the learning effect on the correction of segmentation errors in the images.

The interimage repeatability was calculated using the measurements obtained from the two images. The distribution of the choroidal thickness measurements followed a normal distribution (Shapiro-Wilk tests, $\mathrm{p}>0.05$ ) and therefore parametric statistical analyses were used. The two measurements were compared using paired t-tests and the relationship between the mean and the difference of measurements was checked using Pearson's correlation test. The mean interimage differences and LoA of the differences were determined and plotted as suggested by Bland and Altman. ${ }^{5758}$ Since the repeatability of the same method was being tested on two consecutive OCT scans, the mean difference should be mimimal. The CR can be calculated as twice the SD of the difference between two measurements. ${ }^{57}$ The average of two choroidal thickness measurement was also reported. A probability $(p)$ value of less than 0.05 was chosen to indicate statistical significance. All statistical analyses were performed using SPSS data analysis software (SPSS V.22).

\section{RESULTS}

The SV group comprised 5 males and 15 females with a mean $( \pm \mathrm{SD})$ age of $8.7 \pm 1.1$ years, whereas the ortho-k group consisted of 7 males and 13 females aged 9.4 \pm 1.0 years. The baseline age of SV subjects were younger than those of ortho-k subjects (unpaired t-test, $\mathrm{p}=0.043$ ). However, the baseline refractive errors, including sphere, cylinder, and spherical equivalent refraction, were not significantly different between two groups (unpaired t-tests, $\mathrm{p}>0.05$; table 1$)$. The mean $( \pm \mathrm{SD})$ choroidal thicknesses obtained were not significantly different between groups (unpaired t-test, $\mathrm{p}>0.05$; SV: $227.3 \pm 42.2 \mu \mathrm{m}$; ortho-k: $251.1 \pm 54.4 \mu \mathrm{m})$.

The choroidal thickness measurements from the two images were not significantly different for both groups

\begin{tabular}{|c|c|c|}
\hline & $\begin{array}{l}\text { Single-vision } \\
\text { spectacles }(n=20)\end{array}$ & $\begin{array}{l}\text { Orthokeratology } \\
(n=20)\end{array}$ \\
\hline Age (y) & $8.7 \pm 1.1$ & $9.4 \pm 1.0$ \\
\hline Sphere (D) & $-2.03 \pm 0.81$ & $-2.36 \pm 0.93$ \\
\hline Cylinder (D) & $-0.43 \pm 0.42$ & $-0.55 \pm 0.48$ \\
\hline $\begin{array}{l}\text { Spherical equivalent } \\
\text { refraction (D) }\end{array}$ & $-2.24 \pm 0.85$ & $-2.64 \pm 1.09$ \\
\hline
\end{tabular}



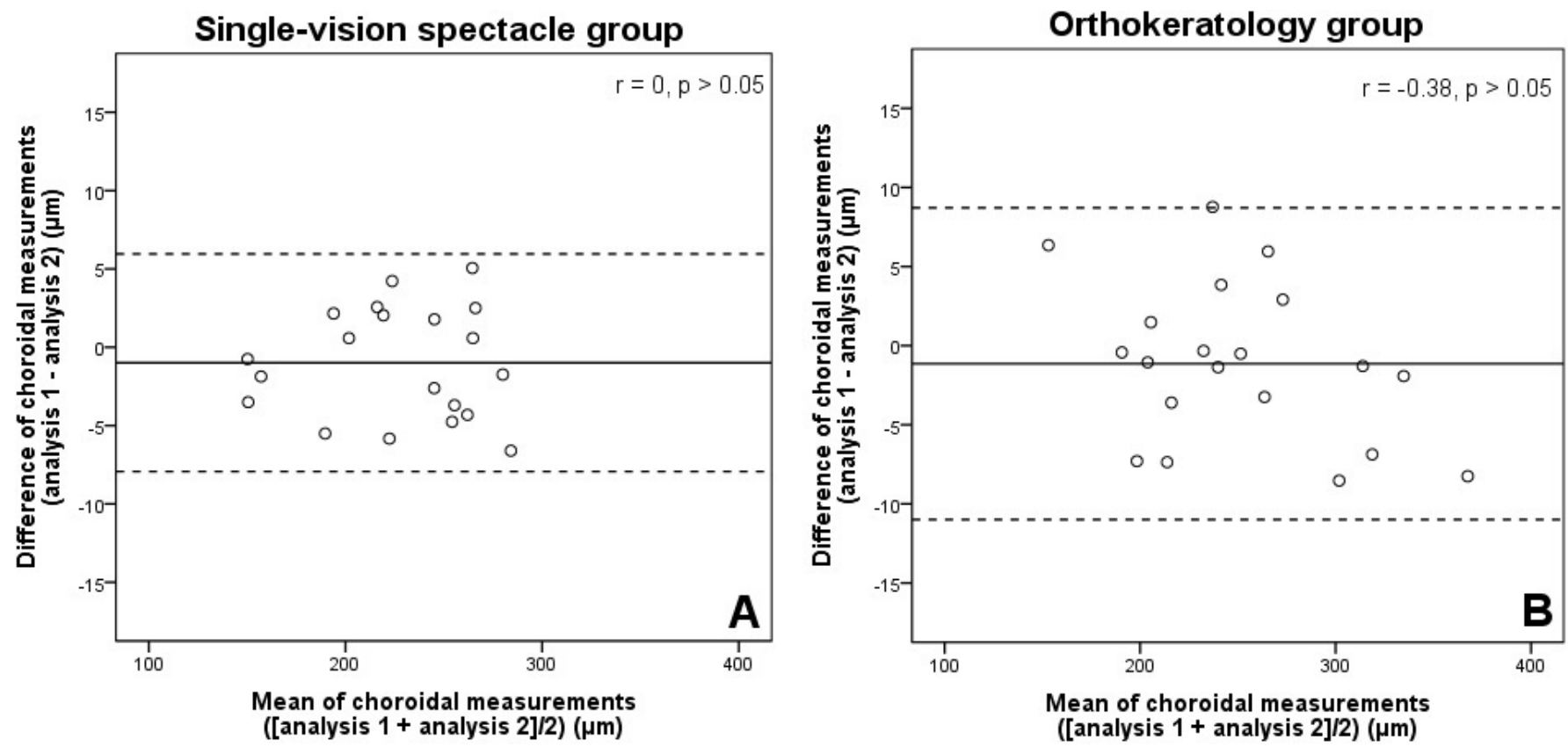

Figure 2 Bland and Altman plots of between-measurement differences against means of choroidal thickness measurements for the interimage repeatability in $(A)$ single-vision spectacle-wearing $(n=20)$ and $(B)$ orthokeratology-treated ( $n=20)$ groups. All Pearson's correlation coefficients $(r)$ showed no significant correlations between the differences and the means of choroidal measurements ( $p>0.05)$. The solid line represents the mean difference of choroidal measurements and the dashed lines represent the lower and upper 95\% limits of agreement (mean difference $\pm 1.96 \times$ SD of the differences).

of subjects (paired t-tests, $\mathrm{p}>0.05$ ). There were no significant correlations between the differences and the means of choroidal thickness measurements in either group $(-0.38<$ Pearson's $\mathrm{r}<0, \mathrm{p}>0.05)$. The mean interimage differences were $-0.99 \pm 3.54$ and $-1.14 \pm 5.03 \mu \mathrm{m}$ for the SV and ortho-k subjects, respectively. For the SV group, the LoA was +5.96 to $-7.93 \mu \mathrm{m}$, and for the ortho-k group, the LoA was +8.72 to $-11.00 \mu \mathrm{m}$. The CRs were 7.08 and $10.06 \mu \mathrm{m}$ for the SV and ortho-k groups, respectively. Figure 2 shows the Bland and Altman plots of the interimage differences and their means.

\section{DISCUSSION}

This study showed that using a written graph-theory-based software to segment EDI-OCT images produced a repeatability of choroidal thickness measurement of approximately 7 and $10 \mu \mathrm{m}$ in children wearing SV spectacles and ortho-k lenses, respectively. Previous studies ${ }^{30343538}$ have segmented the choroidal thickness manually, while others ${ }^{38} 59$ have applied algorithm-based software for automatic segmentation and measurement of choroidal thickness. While the CR estimate is useful in setting an assessment tool of minimal detectable change, ${ }^{6061}$ our results of a CR of approximately $10 \mu \mathrm{m}$ indicated that automatic measurement of choroidal thickness was more repeatable than other studies solely using manual segmentation (CR of about $35 \mu \mathrm{m}$ ). ${ }^{30} 34$ Our results were comparable to the interobserver repeatability results obtained by Li et $a l,{ }^{53}$ whose CRs of SV and ortho-k groups were 9.12 and $6.58 \mu \mathrm{m}$, respectively. However, the challenges involved in fully manual segmentation include weak signals resulting from deeper structures, the vascular nature of the choroidal tissue and varying thickness of choroid. $^{30} 3762$ With the introduction of an automated segmentation technique, researchers require less time for segmentation procedures and this reduces subjective variation in determining the choroidal boundaries and therefore the measurement of its thickness.

Researchers have developed different algorithms for automated segmentation of the choroid. The software used in this study, previously described by Alonso-Caneiro et $a l^{37}$ uses a combination of an edge filter and a directional weighted map penalty to detect the inner choroidal boundary and a dual brightness probability gradient for the detection of the outer choroidal boundary. $^{37}$ Other studies have applied different approaches, including dynamic programming, ${ }^{62} 63$ graph search method, ${ }^{62}$ statistical modelling, ${ }^{63} 64$ estimated morphological modelling, ${ }^{64}$ active contour modelling, ${ }^{65}$ Gaussian mixture modelling ${ }^{66}$ and a combination of polarisation and birefringence ${ }^{67}$ to differentiate the boundaries. Compared with the software developed by Twa et $a l,{ }^{38}$ whose LoA was $\pm 14 \mu \mathrm{m}$, the performance of this software (LoA of +5.96 to -7.93 and +8.72 to $-11.00 \mu \mathrm{m}$ for the SV and ortho-k groups, respectively) was slightly better. Different algorithms could result in discrepancies in the detection of choroidal boundaries due to variations in graph analysis methods. Further investigation of the repeatability of different automatic segmentations of choroidal thickness may warrant their use in detecting subtle choroidal changes, such as diurnal variation, early detection of ocular diseases or responses to optical defocus. 
Read et al's study, ${ }^{59}$ which investigated the longitudinal changes in choroidal thickness in children, reported that a semiautomated method of choroidal thickness (automatic detection for the inner choroidal boundary and manual segmentation for the outer boundary) produced an excellent interimage repeatability for the subfoveal choroidal thickness with an LoA of approximately $\pm 4 \mu \mathrm{m}$, which was almost the axial resolution of the instrument $(3.9 \mu \mathrm{m})$. They used high-resolution acquisition mode, which could produce double the number of A-scans (1536 scans) compared with the 768 scans we captured under high-speed mode. However, the difference in the number of A-scans would only affect the lateral resolution and have minimal influence on subfoveal choroidal thickness measurement. A study which compared the two acquisition modes for measurement of the retinal nerve fibre layer thickness found no significant difference between the results. ${ }^{68}$ However, the high-resolution mode requires longer acquisition time and some children might not be able to maintain steady fixation during the scanning procedures. ${ }^{59}$ The variability in choroidal thickness obtained using these two modes is yet to be confirmed. Another possible reason for the discrepancy in measurements are the subjective procedures involved in segmenting or correcting the choroidal boundaries. Different levels of experience of the observer in choroidal segmentation could lead to possible errors in the measurement.

The CR for interimage analysis was approximately $10 \mu \mathrm{m}$. Although measurement error from scan misalignment was minimised by using the Auto Rescan function for tracking the same retinal location, a possible lateral measurement error of $11 \mu \mathrm{m}$ could still result due to the instrument's limitation, which might lead to inconsistent measurement of the same exact location. Errors can also result from subjective judgement in correcting segmentation errors and determination of the centre of the foveal pit.

A larger variability in choroidal thickness measurement was observed in our ortho-k children. As previously reported, central flattening and midperipheral steepening were observed in corneas after wearing ortho-k lenses. ${ }^{55}$ These changes result in hyperopic shifts in the peripheral refractive powers, but only at some midperipheral regions of the cornea. ${ }^{69}$ Therefore, the correcting lens in the Spectralis OCT may not be able to provide completely in-focus images. In Li $e t a l$ s study, ${ }^{53}$ they found that manual segmentation of EDI-OCT images to be slightly more repeatable for ortho-k subjects compared with SV children. However, in both studies, the differences in CR between SV and ortho-k groups were about 3 $\mu \mathrm{m}$, which was less than the axial resolution $(3.9 \mu \mathrm{m})$ of the instrument and this difference may not be significant.

Our study used images of consecutive scans which eliminates possible diurnal variation of the choroid and the influence of other ocular components on its thickness within the day. ${ }^{70}$ A strength of the study was that children were included. While different populations may show different repeatability errors, ${ }^{37}$ our results helped to identify minimal detectable changes of choroidal thickness in ortho-k treated children. Apart from indicating that all children were able to successfully undergo OCT scans under the high-speed scanning mode, the involvement of ortho-k treated children in our study help to identify real changes in choroidal thickness, despite the influence on the optics of the eye from corneal reshaping. A limitation of the study was that the association between the effects of changes in corneal shape on OCT images and choroidal thickness measurement was not studied. Further investigation on the repeatability of choroidal thickness measurement in subjects with distorted or reshaped optical components, such as keratoconus and LASIK-treated subjects, may help to identify the possible reasons of slightly larger variation in choroidal thickness measurement in the ortho-k children.

\section{CONCLUSION}

In conclusion, our results show that using an automated algorithm produces a good repeatability of choroidal thickness measurement in Chinese children. A subfoveal choroidal change of more than $10 \mu \mathrm{m}$ is likely to be a real detectable change in ortho-k wearing children.

Acknowledgements The authors thank Stephen J Vincent and David AlonsoCaneiro (Contact Lens and Visual Optics Laboratory, Queensland University of Technology) for the advice and the use of the custom written software for choroidal thickness measurements, Kin Wan and Carmen Wong for their assistance with capturing of the OCT scans and choroidal segmentation, respectively.

Contributors JKL, SWC and PC designed and planned the study. JKL conducted the experiment, analysed the data and wrote the first draft of the paper. JKL and PC interpreted the results. All authors revised the manuscript and approved the final version of the work.

Funding This study was supported by a collaborative agreement between The Hong Kong Polytechnic University (PolyU) and Menicon Co., Japan (ZG3Z) and the Research Residency Scheme of the School of Optometry, PolyU.

Competing interests None declared.

Patient consent for publication Not required.

Provenance and peer review Not commissioned; externally peer reviewed.

Open access This is an open access article distributed in accordance with the Creative Commons Attribution Non Commercial (CC BY-NC 4.0) license, which permits others to distribute, remix, adapt, build upon this work non-commercially, and license their derivative works on different terms, provided the original work is properly cited, appropriate credit is given, any changes made indicated, and the use is non-commercial. See: http://creativecommons.org/licenses/by-nc/4.0/.

\section{REFERENCES}

1. Parver LM. Temperature modulating action of choroidal blood flow. Eye 1991;5:181-5.

2. Bill $A$, Hellsing K. Production and drainage of aqueous humor in the cynomolgus monkey (Macaca irus). Invest Ophthalmol Vis Sci 1965;4:920-6.

3. Wallman J, Wildsoet C, Xu A, et al. Moving the retina: Choroidal modulation of refractive state. Vision Res 1995;35:37-50.

4. Wildsoet C, Wallman J. Choroidal and scleral mechanisms of compensation for spectacle lenses in chicks. Vision Res 1995;35:1175-94.

5. Hu W, Criswell MH, Fong S-L, et al. Differences in the temporal expression of regulatory growth factors during choroidal neovascular development. Exp Eye Res 2009;88:79-91.

6. Nickla DL, Wallman J. The multifunctional choroid. Prog Retin Eye Res 2010;29:144-68.

7. Nickla DL, Wildsoet C, Wallman J. Compensation for spectacle lenses involves changes in proteoglycan synthesis in both the sclera and choroid. Curr Eye Res 1997;16:320-6. 
8. Read SA, Collins MJ, Sander BP. Human optical axial length and defocus. Invest Ophthalmol Vis Sci 2010;51:6262-9.

9. Chiang ST-H, Phillips JR, Backhouse S. Effect of retinal image defocus on the thickness of the human choroid. Ophthalmic Physiol Opt 2015;35:405-13.

10. Wang D, Chun RKM, Liu M, et al. Optical defocus rapidly changes choroidal thickness in schoolchildren. Plos One 2016;11:e0161535.

11. Curtin BJ, Karlin DB. Axial length measurements and fundus changes of the myopic eye. Am J Ophthalmol 1971;71:42-53.

12. Pavlin CJ, Harasiewicz K, Foster FS. Ultrasound biomicroscopy of anterior segment structures in normal and glaucomatous eyes. Am J Ophthalmol 1992;113:381-9.

13. Coleman DJ, Silverman RH, Chabi A, et al. High-resolution ultrasonic imaging of the posterior segment. Ophthalmology 2004:111:1344-51.

14. Fraunfelder FT, Fraunfelder FW, Chambers WA. Drug-induced ocular side effects: clinical ocular toxicology. Saint Louis, United States: Elsevier Health Sciences, 2014

15. Tehrani M, Krummenauer F, Blom E, et al. Evaluation of the practicality of optical biometry and applanation ultrasound in 253 eyes. J Cataract Refract Surg 2003;29:741-6.

16. Spaide RF, Koizumi H, Pozzoni MC, et al. Enhanced depth imaging spectral-domain optical coherence tomography. Am J Ophthalmol 2008;146:496-500.

17. Ikuno $\mathrm{Y}$, Kawaguchi $\mathrm{K}$, Nouchi $\mathrm{T}$, et al. Choroidal thickness in healthy Japanese subjects. Invest Ophthalmol Vis Sci 2010;51:2173-6.

18. Fujiwara A, Shiragami C, Shirakata $Y$, et al. Enhanced depth imaging spectral-domain optical coherence tomography of subfoveal choroidal thickness in normal Japanese eyes. Jpn J Ophthalmol 2012;56:230-5.

19. Kim M, Kim SS, Koh HJ, et al. Choroidal thickness, age, and refractive error in healthy Korean subjects. Optom Vis Sci 2014;91:491-6.

20. Phasukkijwatana N, Thaweerattanasilp W, Laotaweerungsawat S, et al. Enhanced depth imaging spectral-domain optical coherence tomography of the choroid in Thai population. J Med Assoc Thai 2014;97:947-53.

21. Tuncer I, Karahan E, Zengin MO, et al. Choroidal thickness in relation to sex, age, refractive error, and axial length in healthy Turkish subjects. Int Ophthalmol 2015;35:403-10.

22. Tsuiki E, Suzuma K, Ueki R, et al. Enhanced depth imaging optical coherence tomography of the choroid in central retinal vein occlusion. Am J Ophthalmol 2013;156:543-7.

23. Nakayama $M$, Keino $H$, Okada $A A$, et al. Enhanced depth imaging optical coherence tomography of the choroid in VOGT-KOYANAGIHARADA disease. Retina 2012;32:2061-9.

24. Taki W, Keino H, Watanabe T, et al. Enhanced depth imaging optical coherence tomography of the choroid in recurrent unilateral posterior scleritis. Graefes Arch Clin Exp Ophthalmol 2013;251:1003-4.

25. Blackburn J, McGwin G. Enhanced depth imaging optical coherence tomography of the choroid in idiopathic macular hole. Am J Ophthalmol 2011;151:560-1.

26. Imamura Y, Fujiwara T, Margolis RON, et al. Enhanced depth imaging optical coherence tomography of the choroid in central serous chorioretinopathy. Retina 2009;29:1469-73.

27. Ayton LN, Guymer RH, Luu CD. Choroidal thickness profiles in retinitis pigmentosa. Clin Experiment Ophthalmol 2013;41:396-403.

28. Chhablani J, Barteselli G, Wang $\mathrm{H}$, et al. Repeatability and reproducibility of manual choroidal volume measurements using enhanced depth imaging optical coherence tomography. Invest Ophthalmol Vis Sci 2012;53:2274-80.

29. Cho AR, Choi YJ, Kim YT. Influence of choroidal thickness on subfoveal choroidal thickness measurement repeatability using enhanced depth imaging optical coherence tomography. Eye 2014;28:1151-60.

30. Rahman W, Chen FK, Yeoh J, et al. Repeatability of manual subfoveal choroidal thickness measurements in healthy subjects using the technique of enhanced depth imaging optical coherence tomography. Invest Ophthalmol Vis Sci 2011;52:2267-71.

31. Yamashita T, Yamashita T, Shirasawa M, et al. Repeatability and reproducibility of subfoveal choroidal thickness in normal eyes of Japanese using different SD-OCT devices. Invest Ophthalmol Vis Sci 2012;53:1102-7.

32. XQ L, Larsen M, Munch IC. Subfoveal choroidal thickness in relation to sex and axial length in 93 Danish university students. Invest Ophthalmol Vis Sci 2011;52:8438-41.

33. Sim DA, Keane PA, Mehta $\mathrm{H}$, et al. Repeatability and reproducibility of choroidal vessel layer measurements in diabetic retinopathy using enhanced depth optical coherence tomography. Invest Ophthalmol Vis Sci 2013;54:2893-901.
34. Hanumunthadu D, Ilginis T, Restori M, et al. Spectral-domain optical coherence tomography retinal and choroidal thickness metric repeatability in age-related macular degeneration. Am J Ophthalmol 2016;166:154-61.

35. Boonarpha N, Zheng Y, Stangos AN, et al. Standardization of choroidal thickness measurements using enhanced depth imaging optical coherence tomography. Int J Ophthalmol 2015;8.

36. Mansouri K, Medeiros FA, Tatham AJ, et al. Evaluation of retinal and choroidal thickness by swept-source optical coherence tomography: repeatability and assessment of artifacts. Am J Ophthalmol 2014;157:1022-32.

37. Alonso-Caneiro D, Read SA, Collins MJ. Automatic segmentation of choroidal thickness in optical coherence tomography. Biomed Opt Express 2013;4:2795-812.

38. Twa MD, Schulle KL, Chiu SJ, et al. Validation of macular choroidal thickness measurements from automated SD-OCT image segmentation. Optom Vis Sci 2016;93:1387-98.

39. Holden BA, Fricke TR, Wilson DA, et al. Global prevalence of myopia and high myopia and temporal trends from 2000 through 2050. Ophthalmology 2016;123:1036-42.

40. Rudnicka AR, Kapetanakis VV, Wathern AK, et al. Global variations and time trends in the prevalence of childhood myopia, a systematic review and quantitative meta-analysis: implications for aetiology and early prevention. $\mathrm{Br} J$ Ophthalmol 2016.

41. Saw S-M, Gazzard G, Shih-Yen EC, et al. Myopia and associated pathological complications. Oph Phys Optics 2005;25:381-91.

42. Marcus MW, de Vries MM, Montolio FGJ, et al. Myopia as a risk factor for open-angle glaucoma: a systematic review and metaanalysis. Ophthalmology 2011;118:1989-94.

43. Pierro L, Camesasca FI, Mischi M, et al. Peripheral retinal changes and axial myopia. Retina 1992;12:12-17.

44. Huang J, Wen D, Wang Q, et al. Efficacy comparison of 16 interventions for myopia control in children: a network meta-analysis. Ophthalmology 2016;123:697-708.

45. Cho P, Cheung S-W. Retardation of myopia in Orthokeratology (ROMIO) study: a 2-year randomized clinical trial. Invest Ophthalmol Vis Sci 2012;53:7077-85.

46. Charm J, Cho P. High myopia-partial reduction ortho-k: a 2-year randomized study. Optom Vis Sci 2013;90:530-9.

47. JK S, Tang K, HS B, et al. Orthokeratology for myopia control: a meta-analysis. Optom Vis Sci 2015:92:252-7.

48. Wolffsohn JS, Calossi A, Cho P, et al. Global trends in myopia management attitudes and strategies in clinical practice. Cont Lens Anterior Eye 2016;39:106-16.

49. Cho P, Cheung SW, Edwards M. The longitudinal orthokeratology research in children (LORIC) in Hong Kong: a pilot study on refractive changes and myopic control. Curr Eye Res 2005;30:71-80

50. Walline JJ, Jones LA, Sinnott LT. Corneal reshaping and myopia progression. Br J Ophthalmol 2009;93:1181-5.

51. Kakita T, Hiraoka T, Oshika T. Influence of overnight orthokeratology on axial elongation in childhood myopia. Invest Ophthalmol Vis Sci 2011;52:2170-4.

52. Chen Z, Xue F, Zhou J, et al. Effects of orthokeratology on choroidal thickness and axial length. Optometry and Vision Science 2016;93:1064-71.

53. Li Z, Cui D, Hu Y, et al. Choroidal thickness and axial length changes in myopic children treated with orthokeratology. Contact Lens and Anterior Eye 2017;40:417-23.

54. Gardner DJ, Walline JJ, Mutti DO. Choroidal thickness and peripheral myopic defocus during orthokeratology. Optom Vis Sci 2015;92:579-88.

55. Swarbrick HA, Wong G, O'Leary DJ. Corneal response to orthokeratology. Optom Vis Sci 1998;75:791-9.

56. Ikuno $\mathrm{Y}$, Maruko I, Yasuno $\mathrm{Y}$, et al. Reproducibility of retinal and choroidal thickness measurements in enhanced depth imaging and high-penetration optical coherence tomography. Invest Ophthalmol Vis Sci 2011;52:5536-40.

57. Martin Bland J, Altman D. Statistical methods for assessing agreement between two methods of clinical measurement. The Lancet 1986;327:307-10.

58. Bland JM, Altman DG. Measuring agreement in method comparison studies. Stat Methods Med Res 1999;8:135-60.

59. Read SA, Alonso-Caneiro D, Vincent SJ, et al. Longitudinal changes in choroidal thickness and eye growth in childhood. Invest Ophthalmol Vis Sci 2015;56:3103-12.

60. Vaz S, Falkmer T, Passmore AE, et al. The case for using the repeatability coefficient when calculating test-retest reliability. PLOS ONE 2013;8:e73990.

61. Bland JM, Altman DG. Applying the right statistics: analyses of measurement studies. Ultrasound Obstet Gynecol 2003;22:85-93. 
62. Tian J, Marziliano P, Baskaran M, et al. Automatic measurements of choroidal thickness in EDI-OCT images. Conf Proc IEEE Eng Med Biol Soc 2012;2012:5360-3.

63. Kajić V, Esmaeelpour M, Považay B, et al. Automated choroidal segmentation of $1060 \mathrm{~nm}$ OCT in healthy and pathologic eyes using a statistical model. Biomed Opt Express 2012;3:86-103.

64. Hu Z, Wu X, Ouyang Y, et al. Semiautomated segmentation of the choroid in spectral-domain optical coherence tomography volume scans. Invest Ophthalmol Vis Sci 2013;54:1722-9.

65. Lu H, Boonarpha N, Kwong MT, et al. Automated segmentation of the choroid in retinal optical coherence tomography images. Conf Proc IEEE Eng Med Biol Soc 2013;2013:5869-72.

66. Danesh H, Kafieh R, Rabbani H, et al. Segmentation of choroidal boundary in enhanced depth imaging OCTs using a multiresolution texture based modeling in graph cuts. Comput Math Methods Med 2014;2014:1-9.
67. Torzicky T, Pircher M, Zotter S, et al. Automated measurement of choroidal thickness in the human eye by polarization sensitive optical coherence tomography. Opt. Express 2012;20:7564-74.

68. Serbecic N, Beutelspacher SC, Aboul-Enein FC, et al.

Reproducibility of high-resolution optical coherence tomography measurements of the nerve fibre layer with the new Heidelberg spectralis optical coherence tomography. $\mathrm{Br} \mathrm{J}$ Ophthalmol 2011;95:804-10.

69. Kang P, Swarbrick H. Time course of the effects of orthokeratology on peripheral refraction and corneal topography. Ophthalmic Physiol Opt 2013;33:277-82.

70. Read SA, Collins MJ, Iskander DR. Diurnal variation of axial length, intraocular pressure, and anterior eye biometrics. Invest Ophthalmol Vis Sci 2008;49:2911-8.

71. Chakraborty R, Read SA, Collins MJ. Diurnal variations in axial length, choroidal thickness, intraocular pressure, and ocular biometrics. Invest Ophthalmol Vis Sci 2011;52:5121-9. 